\title{
Role of RNA-binding proteins during the late stages of Flavivirus replication cycle
}

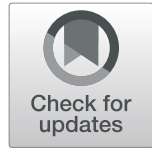

Mayra Diosa-Toro ${ }^{*}$, K. Reddisiva Prasanth ${ }^{2}$, Shelton S. Bradrick $2,3,4$ and Mariano A. Garcia Blanco 1,2,4*

\begin{abstract}
The genus Flavivirus encompasses several worldwide-distributed arthropod-borne viruses including, dengue virus, Japanese encephalitis virus, West Nile virus, yellow fever virus, Zika virus, and tick-borne encephalitis virus. Infection with these viruses manifest with symptoms ranging from febrile illness to life- threatening hypotensive shock and encephalitis. Therefore, flaviviruses pose a great risk to public health. Currently, preventive measures are falling short to control epidemics and there are no antivirals against any Flavivirus.

Flaviviruses carry a single stranded positive-sense RNA genome that plays multiple roles in infected cells: it is translated into viral proteins, used as template for genome replication, it is the precursor of the subgenomic flaviviral RNA and it is assembled into new virions. Furthermore, viral RNA genomes are also packaged into extracellular vesicles, e.g. exosomes, which represent an alternate mode of virus dissemination.

Because RNA molecules are at the center of Flavivirus replication cycle, viral and host RNA-binding proteins (RBPs) are critical determinants of infection. Numerous studies have revealed the function of RBPs during Flavivirus infection, particularly at the level of RNA translation and replication. These proteins, however, are also critical participants at the late stages of the replication cycle. Here we revise the function of host RBPs and the viral proteins capsid, NS2A and NS3, during the packaging of viral RNA and the assembly of new virus particles. Furthermore, we go through the evidence pointing towards the importance of host RBPs in mediating cellular RNA export with the idea that the biogenesis of exosomes harboring Flavivirus RNA would follow an analogous pathway.
\end{abstract}

Keywords: RNA-binding proteins, Flavivirus infection, Viral assembly, RNA export, Exosomes

\section{Background} Introduction

The Flaviviridae is a family composed of a large number of enveloped positive-strand RNA viruses, many of which pose serious risks to human health on a global scale. This virus family name is derived from the prototype member: the deadly yellow (flavus) fever virus (YFV). In 1882, Carlos Finlay suggested that Culex cubensis (now known as Aedes aegypti) was the mosquito responsible for the transmission of yellow fever, but he was unable to prove his hypothesis [1]. Almost

\footnotetext{
* Correspondence: mayra.diosa@duke-nus.edu.sg; maragarc@utmb.edu ${ }^{1}$ Programme in Emerging Infectious Diseases, Duke-NUS Medical School, Singapore, Singapore

Full list of author information is available at the end of the article
}

two decades later, in 1901, Walter Reed's research proved that yellow fever was indeed transmitted by $A e-$ des aegypti mosquitoes and caused by a filterable agent found in the blood of infected patients [2]. Decades later the causative virus was isolated and, with the advent of tissue culture methods, passaged extensively by Max Theiler and colleagues, leading to isolation of an attenuated strain (17D) that would later serve as a highly effective vaccine and earn Theiler a Nobel Prize in Physiology or Medicine [3].

The most recent classification of the Flaviviridae by the International Committee on Taxonomy of Viruses names 89 species divided between four genera within the family: Flavivirus, Hepacivirus, Pegivirus and Pestivirus. This review will focus on the genus Flavivirus,

\section{$\triangle B M C$}

(c) The Author(s). 2020 Open Access This article is licensed under a Creative Commons Attribution 4.0 International License, which permits use, sharing, adaptation, distribution and reproduction in any medium or format, as long as you give appropriate credit to the original author(s) and the source, provide a link to the Creative Commons licence, and indicate if changes were made. The images or other third party material in this article are included in the article's Creative Commons licence, unless indicated otherwise in a credit line to the material. If material is not included in the article's Creative Commons licence and your intended use is not permitted by statutory regulation or exceeds the permitted use, you will need to obtain permission directly from the copyright holder. To view a copy of this licence, visit http://creativecommons.org/licenses/by/4.0/ The Creative Commons Public Domain Dedication waiver (http://creativecommons.org/publicdomain/zero/1.0/) applies to the data made available in this article, unless otherwise stated in a credit line to the data. 
which is subdivided into four ecological groups: mosquitoborne, tick-borne, insect-specific and no known arthropod vector flaviviruses $[4,5]$. The vast majority of research relevant to this review has been performed with mosquito and tick-borne flaviviruses including dengue virus (DENV), Japanese encephalitis virus (JEV), West Nile virus (WNV), YFV, Zika virus (ZIKV), and tick-borne encephalitis virus (TBEV). These viruses are of clinical importance as they cause major outbreaks with a variety of disease symptoms including hemorrhagic fever and encephalitis [6]. DENV in particular is a significant human health concern as it is ubiquitous in the tropics and estimated to cause nearly 100 million symptomatic infections per year [7]. The severe manifestation of human DENV infection is dengue hemorrhagic fever and dengue shock syndrome, which can be lethal, especially for patients lacking supportive care.

Vector control strategies are the main countermeasures to limit the burden of Flavivirus-related diseases; however, traditional methods have failed mainly due to insecticide resistance [8]. Furthermore, although several trials involving mosquito population suppression/replacement are undergoing [9], these are likely to pose complex challenges mainly related to implementation, coverage and public acceptance. Currently, effective vaccines are in use for YFV, JEV and TBEV [10-12]. The development of an effective vaccine against DENV has proven challenging, with recent concerns raised regarding the safety of the only licensed vaccine $[13,14]$. Nonetheless, encouraging clinical trials suggest the development of a safe and effective tetravalent DENV vaccine in the near future [15]. At this time, there is no specific antiviral therapy against any virus of the Flavivirus genus. Thus, although progress has been made to limit the burden of flaviviruses epidemics, more work needs to be done. In particular, there are concerns about emerging viruses with novel pathogenic potential, exemplified by the recent ZIKV pandemic and its association with birth defects [16].

\section{Characteristics of Flavivirus virions and genome organization}

Flaviviruses are enveloped viruses in which the viral RNA (vRNA) and capsid (C) protein are surrounded by a lipid bilayer derived from the host cell. Embedded in this outer layer, two viral glycoproteins are found: envelope (E) and Membrane (M) [17]. The structures of multiple flaviviruses have been solved and the arrangement and stoichiometry of $\mathrm{M}$ and $\mathrm{E}$ have been well characterized in both mature and immature virions; the latter have an uncleaved version of $\mathrm{M}$ referred to as prM [18, 19]. Within the interior of the virion is the nucleocapsid, formed by the positive-sense single stranded vRNA genome associated with $C$ protein. Infectious Flavivirus particles are relatively uniform in size $(\sim 50 \mathrm{~nm}$ in diameter $)$ and density (1.19 to $1.23 \mathrm{~g} / \mathrm{cm}^{3}$ ) [17], but infected cells also produce smaller $(\sim 30 \mathrm{~nm}$ in diameter $)$, noninfectious enveloped particles that contain $\mathrm{M}$ and $\mathrm{E}$ proteins but lack nucleocapsid [20].

The Flavivirus genome is around $11 \mathrm{~kb}$ in length, carries a type 1 cap (m7GpppAmp) structure at the $5^{\prime}$ end and lacks a poly(A) tail at the $3^{\prime}$ end $[21,22]$. The single open reading frame (ORF) is flanked by highly structured $5^{\prime}$ and $3^{\prime}$ untranslated regions (UTRs) involved in translation, replication and likely packaging of the vRNA. The 5' UTR is relatively short ( $100 \mathrm{nt})$ and carries a large stem-loop (SLA) that functions as promoter for the viral polymerase, NS5, to initiate RNA synthesis at the 3' end of a 'circularized' genome [23]. The 3' UTR is larger $(\sim 400$ to $700 \mathrm{nt})$ and includes three distinct domains. Domain 1, which is the least conserved among flaviviruses, is known as the 'variable region' and contains two stem-loop structures (SLI and SLII) that form pseudoknots with adjacent sequences; domain 2 includes either one (e.g., ZIKV and YFV) or two (e.g., DENV and JEV) conserved dumbbell structures (DB1 and DB2) [24]. The structures present in domain 1 facilitate but are considered dispensable for replication [2527]. Finally, domain 3, the most conserved region of the 3' UTR, contains a complementary sequence element (CS1) followed by a terminal stem-loop structure (3' SL) $[22,28]$. Both, CS1 and portions of the $3^{\prime}$ SL are complementary to sequences present at the $5^{\prime}$ end and thus, allow the circularization of the RNA genome, a step required prior to vRNA replication [23].

In addition to its role during vRNA replication, the Flavivirus 3' UTR is the precursor of the subgenomic flaviviral RNA (sfRNA). sfRNA results from partial degradation of vRNA by the host $5^{\prime} \rightarrow 3^{\prime}$ exoribonuclease XRN1, which stalls at exonuclease resistant RNA structures (xrRNAs) present in the 3' UTR [29, 30]. The Flavivirus 3' UTR contains up to four xrRNAs, corresponding with compactly folded RNA elements found in the SL and DB structures. In some instances, XRN1 slips through the first xrRNA and stalls at a downstream structure giving rise to sfRNAs of different lengths [31, 32]. The production of sfRNA is independent of virus replication and viral proteins and is conserved in all flaviviruses studied thus far $[29,33,34]$. Its functions relate to pathogenicity, inhibition of antiviral responses, increased viral transmission and higher replicative fitness [29, 35-38].

\section{Flavivirus replication cycle}

Flaviviruses enter a susceptible host cell by receptormediated endocytosis. There is not a single receptor for these viruses; rather binding of $\mathrm{E}$ to various membranebound molecules has been shown to mediate entry. Possible receptors include $\alpha_{v} \beta_{3}$ integrins, C-type lectin receptors (CD206, CD209, CLEC5A), TIM/TAM phosphatidylserine 


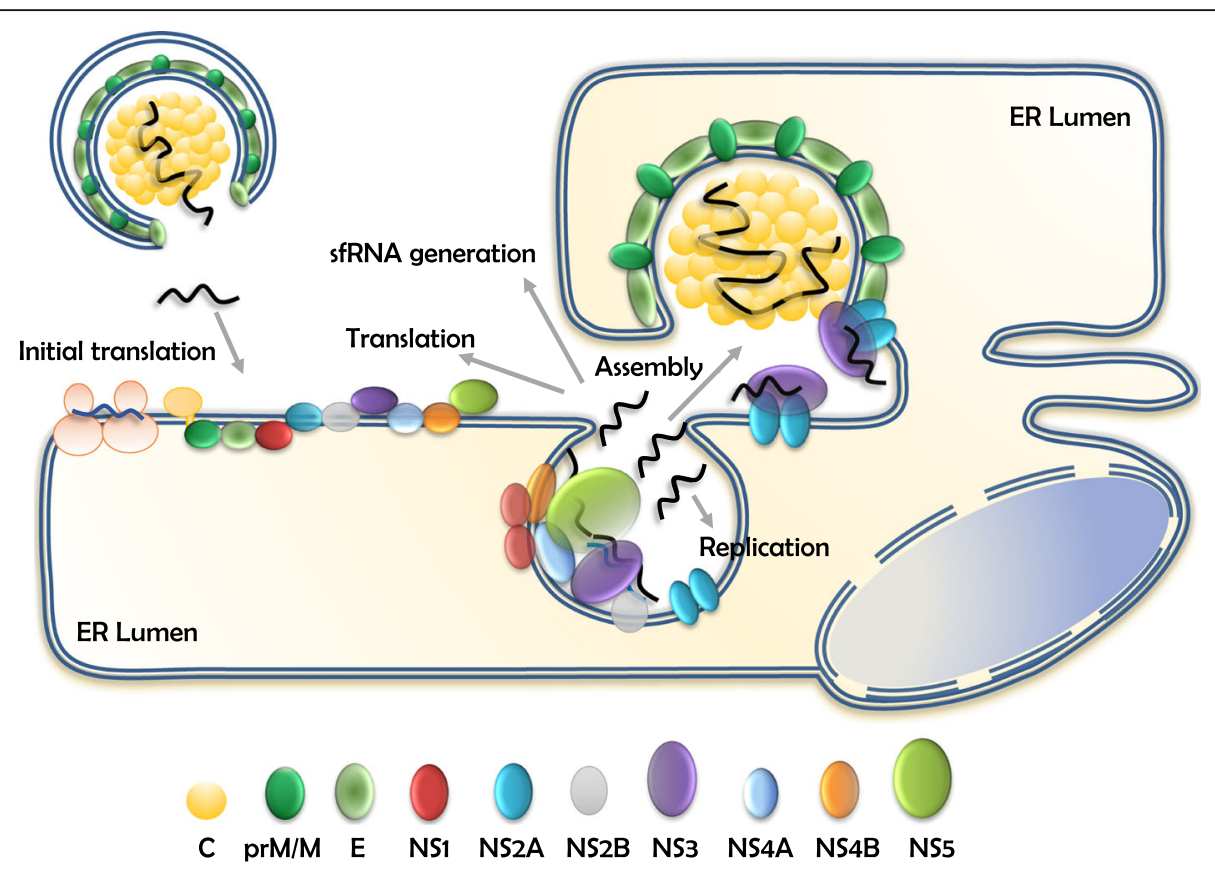

Fig. 1 RNA transactions in Flavivirus-infected cells. Flaviviruses carry a positive-sense RNA that is immediately translated upon delivery into a susceptible host cell. Translation takes place at the ER membrane and generates a single polyprotein processed into three structural proteins (C, prM/M and E) and seven non-structural (NS) proteins. Replication of vRNA takes place inside virus-induced invaginations known as vesicle packets (VPs). Newly synthesized vRNA function as template for translation, further replication, generation of sfRNA molecules or is assembled into new virus particles. Assembly takes place at locations juxtaposed to the VPs. The viral proteins NS2A and NS3 have been implicated in the assembly of new virus particles

receptors, heat shock proteins 70 and 90 , among others [39-41]. In addition, virus particles opsonized with immunoglobulins, which are present during secondary DENV infections, mediate entry in cells bearing Fc receptors [42]. Internalization of the viral particle occurs mainly through clathrin-mediated endocytosis which delivers virus particles to the early endosome $[43,44]$. Maturation from early to late endosomes with a concomitant drop in $\mathrm{pH}$ favours conformational changes in the viral $\mathrm{E}$ protein resulting in its fusion with host cell membranes [45]. Following the fusion step, the viral RNA (vRNA) is released into the cytoplasm. The process of uncoating, e.g. the disassembly of the viral ribonucleoprotein (RNP) complex, is not completely understood, but it has been suggested that a non-degradative ubiquitination of $\mathrm{C}$, mediated by E1-activating enzyme is required for genome uncoating [46]. We have previously proposed a model in which elongating ribosomes drive the release of $C$ from the vRNA [47], but this remains to be investigated.

Once in the cytoplasm the vRNA is transported to the endoplasmic reticulum (ER) where translation takes place [48]. The vRNA has a type 1 cap structure and therefore, translation is considered to be cap-dependent, like the majority of the eukaryotic mRNAs [49]; however, non-canonical mechanisms of translation initiation have also been described for DENV [50-52]. Translation and concomitant processing of the ER-bound polyprotein generates three structural proteins $(\mathrm{C}, \mathrm{prM} / \mathrm{M}$ and E) and seven non-structural (NS) proteins [53]. The NS proteins include NS3 and NS5, which carry enzymatic activities (NS3 is a protease and helicase while NS5 is a RNA-dependent RNA polymerase (RdRp) and methyltransferase), and NS1, NS2A, NS2B, NS4A, and NS4B, which participate in vRNA replication and virion assembly [54].

Viral non-structural proteins mediate vRNA replication, which occurs within virus-induced ER invaginations, known as vesicle packets (VPs). The components of the replication complex, vRNA, NS proteins and possibly host factors, are found inside VPs [55]. VPs are connected to the cytoplasm via a pore, through which other factors needed for replication such as nucleotides can enter $[55,56]$. Using the viral genome as template, NS5 synthesizes antisense (-)RNA, generating double stranded (ds) RNA replicative intermediates. The (-)RNA serves as template for additional positive-sense vRNA synthesis.

Newly synthesized vRNAs exit through the pore of VPs and serve multiple purposes. They are used to translate viral proteins, function as template for (-)RNA synthesis to generate additional genomes, become the precursors of sfRNA molecules, or are selectively 
packaged into viral particles $[57,58]$. All these processes are tightly coordinated in time and space but little is known about the mechanisms that determine the fate of vRNA molecules at this point. vRNA molecules destined to be part of virions are relocated to the assembly sites (Fig. 1), where the nucleocapsid is formed and newly assembled virus particles containing $\mathrm{E}$ and prM bud into the ER lumen (details of this step will be discussed below). These immature virions are transported via the secretory pathway where the slightly acidic $\mathrm{pH}(\sim 5.8-$ 6.0) of the trans-Golgi network triggers conformational changes of E/prM $[18,19]$. Such changes expose a cleavage site for the cellular protease furin that releases the pr-peptide from the M protein [59]. The cleaved pr fragment remains associated with the virion until the virus is secreted to the extracellular environment [60].

\section{Main text \\ Role of viral and cellular RBPs during the late stages of the replication cycle Viral RNA encapsidation}

The molecular details leading to Flavivirus vRNA encapsidation and assembly into new virions remains largely unknown. Notably, the process is thought to be highlys specific, as only a single full length (+)vRNA molecule is packaged into virions [61], whereas sfRNA molecules, (-)RNA and host RNAs are excluded. The selective packaging of single stranded RNA viruses is often attributed to the presence of packaging signals, specific sequences and/or secondary structures that promote interaction with $C$ proteins [62]. The C-binding signals have not been identified for flaviviruses. Therefore, nonspecific electrostatic interactions between highly basic $\mathrm{C}$ protein and negatively charged vRNA are likely to mediate Flavivirus nucleocapsid formation [63]. Notably, in spite of $\mathrm{C}$ being the least conserved of the Flavivirus viral proteins (less than $40 \%$ sequence identity), the charge distribution is similar among the viruses in the genus [64]. Indeed, mutational analysis of two conserved clusters of basic amino acids revealed that no specific residues were required for DENV virus production as long as the number of positive charges were preserved [65]. The study of Flavivirus particles by cryo-electron microscopy did not visualize an organized nucleocapsid suggesting that it does not have the same symmetry as the envelope or that it is stochastically arrayed, which could be mediated by non-specific interactions between $\mathrm{C}$ and vRNA [66, 67].

Nucleocapsids have not been visualized in Flavivirusinfected cells suggesting that encapsidation is rapid and/ or concurrent with replication and budding. Indeed, Khromykh and collaborators showed that packaging of Kunjin (KUN) WNV vRNA is coupled to active vRNA replication [68]. For their study, the authors designed a
DNA-based KUN replicon that allows the continuous transcription by cellular RNA polymerase II and accumulation of replication-competent (wild-type) and replication-deficient (RdRp-defective) KUN RNAs. As expected, transfection of wild-type DNA constructs yielded replicating KUN RNA and secretion of infectious virions. On the other hand, transfection of the RdRpdefective construct resulted in the cytoplasmic accumulation of RdRp-defective RNA and the secretion of structural proteins; however, this RNA was not packaged into secreted virus particles. Notably, when the RdRpdefective plasmid was transfected into helper BHK-21 cells, which persistently express KUN replicon RNA and thus provide wild-type replicative proteins, the $R \mathrm{dRp}$ defective RNA was packaged and secreted into virus particles [68]. Their results strongly suggest that replication and assembly are coupled. Coupling of vRNA replication with assembly plausibly gives specificity to the encapsidation process and its straightforward to envision a model wherein the vRNA will exit through the pore of the VP which is juxtaposed to the assembly sites at the ER [55].

Further specificity to the encapsidation process could be given by RNA modifications or by interactions of $\mathrm{C}$ and vRNA with viral or host proteins. For example, the vRNA of DENV, ZIKV and Hepatitis C virus (HCV), a member of the Hepacivirus genus of the Flaviviridae family, are targets for N6-methyltransferases within the $E$ and RdRp regions [69]. The presence of this modification in the E region was shown to abrogate HCV vRNA packaging without altering replication, suggesting that the formation of the HCV nucleocapsid is regulated in such way that vRNA lacking the N6-methylation is preferentially packaged into budding virions [69]. Nevertheless, it remains to be established whether this modification is implicated in the regulation of DENV and ZIKV vRNA packaging.

Lastly, several host factors have been found to interact with Flavivirus $\mathrm{C}$ protein with the potential of modulating the encapsidation process. For example, $\mathrm{Li}$ and collaborators identified $70 \mathrm{WNV}$ C-interacting partners, the majority of which are involved in RNA processing [70]. In the same study it is shown that despite the limited sequence similarity between the $\mathrm{C}$ protein from DENV, WNV and ZIKV, there is a significant overlap between their interacting host factors [70]. One of these is the exon-junction complex recycling factor PYM1, a protein involved in non-sense mediated decay (NMD). The authors showed that the NMD pathway is antiviral against WNV, DENV and ZIKV, and that WNV antagonizes this response by binding of C to PYM1, which protects vRNA from NMD-mediated degradation [70]. Other RBPs such as Caprin1, nucleophosmin and hnRNPK were previously shown to bind JEV and DENV C 
protein, respectively [71-74]. These host factors are important for infection given that their knockdown reduced virus titers; however, whether the encapsidation and/or assembly steps were affected by these proteins was not determined. On the contrary, DDX56 and nucleolin are host RBPs described to bind $C$ protein and specifically affect the assembly step of WNV and DENV, respectively [75-78]. We refer to these proteins in a later section.

\section{Post-replicative functions of NS proteins}

The function of Flavivirus NS proteins is best characterized during vRNA replication, however, NS proteins are also required for the assembly and egress of virus particles [79]. Studies on the molecular mechanisms by which NS proteins regulate the late stages of the replication cycle are limited because genetic perturbations of most NS proteins lead to the abrogation of RNA replication. Here, we will discuss recent data pointing towards the essential functions of NS2A and NS3 for assembly.

NS2A Flavivirus NS2A is a small $(\sim 22 \mathrm{KDa})$, hydrophobic protein generated after processing of the viral polyprotein by an unknown host protease and the viral protease at the NS1-NS2 and NS2A-NS2B boundaries, respectively [80]. It contains eight segments which have been named predicted transmembrane segments (pTMS), although only five of them truly transverse the ER membrane. The N-terminus, pTMS1 and pTMS5 localize to the ER lumen and do not interact with its membrane; pTMS2 is in the ER lumen and interacts peripherally with the ER membrane; pTMS3, 4, 6, 7 and 8 are integral transmembrane domains and a short Cterminus localizes to the cytoplasm [81]. Several reports have mapped NS2A residues that are determinants for viral assembly and egress. It has been shown that the mutation Lys-90-Ser or the triple mutation Arg-22-Ala/ Lys-23-Ala/ Arg-24-Ala in YFV NS2A does not affect the accumulation of viral protein or vRNA, but decreases the production of infectious virions [82, 83]. Interestingly, the Lys-90-Ser mutation had no effect on the production of VLPs that lack capsid and vRNA, suggesting that NS2A participates in the incorporation of vRNA into the budding particle [82]. Similarly, an Ile59-Asn mutation impaired the assembly of KUN WNV. The mutation was associated with the absence of the ER membrane remodelling present in cells transfected with a wild-type infectious RNA replicon. Importantly, a compensatory mutation Thr-149-Pro restored the membrane remodelling and virus production to levels similar to wild-type $[84,85]$.

More recently, a detailed mechanism of the function for NS2A during DENV virus assembly was described by Xie and collaborators [86, 87]. The authors reported a set of mutations that specifically impaired virus assembly without affecting vRNA synthesis. These mutants, which were incompetent for viral assembly, (Gly-11-Ala, Glu20-Ala, Glu-100-Ala, Gln-187-Ala, and Lys-188-Ala), could be rescued in trans by expressing wild-type NS2A or a mutant unable to support vRNA replication [86]. Further studies demonstrated that despite similar levels of viral protein synthesis and ER membrane rearrangements between wild-type RNA and the Gly-11-Ala mutant, the latter failed to form viral particles, as assessed by transmission electron microscopy, and reduced release of extracellular vRNA [87]. Moreover, the Gly-11Ala mutant showed a significant decrease in the C-prM cleavage which resulted in an altered cellular localization of $\mathrm{C}$, a decreased expression of $\mathrm{E}$ and an abrogation of prM expression. This defect in C-prM cleavage was explained by enhanced binding of mutant NS2A to prM on the ER lumen, which pulls the $C$ anchor towards the ER membrane making it inaccessible to NS2B/NS3 in the cytoplasmic side. This defect was rescued by trans complementation with wild-type NS2A and several mutations in $\mathrm{C}$ which shifted the C-prM cleavage site by two amino acids. Similarly, ZIKV NS2A was shown to independently bind prM/E and NS2B/NS3 [88] which would facilitate the recruitment of these complexes to the virion assembly site by oligomerization of NS2A.

Several studies have suggested the involvement of NS2A in the transport of vRNA from the replication complexes to the sites of viral assembly, whereby NS2A functions as a viroporin $[85,89]$. Viroporins are hydrophobic proteins that oligomerize at cellular membranes resulting in the formation of an hydrophilic channel that alters membrane permeability, vesicular trafficking and $\mathrm{Ca}^{+2}$ homeostasis [90]. Indeed, overexpression of DENV and JEV NS2A in E. coli resulted in increased membrane permeability and lysis [89, 91]; however, more recent studies point towards a different mechanism by which NS2A transports newly synthesized vRNA. In their study, Xie and collaborators [87] showed that NS2A specifically binds to DENV vRNA, with a cytoplasmic loop of NS2A (amino acids 93 to 100) interacting with the last 285 nucleotides of DENV 3' UTR. Similar findings were reported by the same group for ZIKA NS2A, where the cytoplasmic loop (residues 97 to 104) was shown to interact with the last 333 nucleotides from the 3' UTR [88]. As no RNA packaging signal has been identified for Flavivirus assembly, the authors hypothesize that complex structures located in the 3' UTR of DENV and ZIKA serve as signals for NS2A to recruit newly synthesized vRNA from the replication complex to the viral assembly site. Because mutations that alter virus assembly do not influence the interaction with DENV or ZIKA 3' UTR, the authors propose a model in which different molecules of NS2A recruit C-prM-E, NS2B/NS3 and 
vRNA to the virion assembly site. These molecules are brought together due to oligomerization of NS2A after which processing of the structural proteins occurs yielding free $\mathrm{C}$ that binds to vRNA to form the nucleocapsid on the cytoplasmic side. The nucleocapsid is then enveloped by $\mathrm{E}$ and prM leading to virion formation and budding into the ER lumen [87, 88]. Although the proposed model is very compelling, it remains to be addressed whether interaction of the vRNA with $\mathrm{C}$ will lead to its detachment from NS2A, or whether NS2A is incorporated into the virion. Likewise, Flavivirus infection produce large amounts of sfRNA, as these molecules derive from the 3' UTR from the vRNA, an important question is whether NS2A can bind sfRNA molecules free in the cytoplasm and whether or not these are incorporated into virions.

NS3 Flavivirus NS3 $(\sim 70 \mathrm{KDa})$ is a multifunctional protein with two domains, the $\mathrm{N}$-terminal domain has chymotrypsin-like serine protease activity and the Cterminal domain has helicase, ATPase and RNA $5^{\prime}$ triphosphatase activities [92]. In addition, an ATPindependent RNA annealing activity has also been reported [93]. The protease activity of NS3 is required in cis and trans for processing of the viral polyprotein, whereby NS2B functions as cofactor. The precise function of the helicase domain during vRNA replication is not known, but it is presumed that it resolves secondary structures present in the vRNA, displaces other RNAbinding proteins to remodel the viral RNP, and/or separates the dsRNA intermediate formed upon replication [94]. Together NS3 and NS5 have all the enzymatic activities required for the replication of Flavivirus vRNA, and recently a hand full of studies suggest that the function of NS3 extends outside of the replication complex.

Efficient Flavivirus assembly requires an obligatory sequential cleavage at the C-prM junction by NS2B-NS3 protease at the $\mathrm{C}$ cytosolic side and then by cellular signalase at the ER lumen side. The coordinated processing releases the mature $\mathrm{C}$ protein required for encapsidation $[95,96]$. In addition to enabling the processing of $C$, NS3 appears to have other roles during viral assembly. As Pijlman and collaborators demonstrated, KUN WNV NS3 mutants with defects for $\mathrm{C}$ processing and RNA replication can be rescued in trans, while mutations affecting packaging cannot be complemented with functional NS3 [97]. The authors proposed a model in which newly synthesized NS3 associates with the progeny vRNA template at the same time that it interacts with other viral (or host) proteins. This viral RNP complex is responsible for the re-localization of vRNA to the sites of encapsidation/assembly [97]. Though proposed more than a decade ago, this hypothesis remains valid particularly in light of the new function discovered for NS2A described in the previous section. NS3 is also required for the packaging of YFV vRNA because a single mutation (Trp-349-Ala) in the helicase domain resulted in less infectious virus release without affecting the expression of viral proteins, vRNA replication and release of subviral particles lacking $C$ protein and vRNA [98]. Interestingly, trans complementation with the NS3 mutants S138A or R461Q in which the protease and the helicase are inactive, respectively, rescued virus production, suggesting that the function of NS3 during virus assembly is independent from its known enzymatic activity. Lastly, structural studies suggest that binding of NS3 to specific $5^{\prime}$ UTR sequences could function as a molecular signature to guide newly synthesized vRNA out of the replication complex [99]. Nevertheless, biophysical and biochemical evidence to support this hypothesis is lacking.

Interactions of NS3 with several host factors have also been reported [70, 100]. Of importance for assembly, YFV and DENV NS3 were found to interact with apoptosis linked gene-2-interacting protein X (ALIX) [101, 102]. In both cases knock out of ALIX or transfection with truncated versions of the protein resulted in the inhibition of virus release without affecting vRNA replication. ALIX is an accessory protein for the endosomal sorting complex required for transport (ESCRT) machinery that mediates membrane deformation favouring budding away from the cytoplasm [103]. Several ESCRT subunits are required for the membrane deformation during budding of the Flavivirus viral particle but not for the formation of VPs [104]. Because ALIX plays a role in concentrating cargoes that are incorporated into budding vesicles, is tempting to speculate that its interaction with NS3 mediates proper assembly of viral particles, however, this remains to be examined.

\section{Host cell RBPs with potential roles in virus assembly}

Numerous studies have been undertaken in order to characterize the mechanism by which cellular RBPs regulate Flavivirus replication cycle and we refer the reader to recent reviews on this topic $[57,58,105]$. In most cases, cellular RBPs have been shown to play roles in vRNA translation and replication; however, few of these proteins have been shown to affect Flavivirus infection beyond the replication step. One such example is DDX56, a nucleolar RNA helicase member of the DEAD box protein family [106]. Hobman and collaborators have comprehensively studied the mechanism by which DDX56 regulates the packaging of WNV vRNA. DDX56 was initially identified as a C-interacting partner by the means of yeast two-hybrid screening followed by immunoprecipitation. Importantly this interaction was shown to be RNA-independent [75]. Knockdown of DDX56 in several human-derived cell lines resulted in a significant 
decrease of infectious WNV in the supernatant. The reduced infectivity was associated with a decrease in the amount of vRNA being packaged and secreted in virions given that same levels of WNV C protein were secreted from control and DDX56-knockdown cells [75]. The authors then showed that infectious virus production is rescued in trans by wild-type DDX56 but not by the mutants D166N and E167Q in which the helicase activity is abrogated. Furthermore, over-expression of the Cterminus of DDX56, which was identified as the Cinteracting domain, reduced the amount of secreted vRNA but not secreted $C$. Therefore, the authors proposed that interaction of DDX56 with $\mathrm{C}$ enables loading of vRNA during the assembly of the virus particle [76]. Given these results and because during WNV infection DDX56 relocates from the nucleus to the cytoplasm [75], it was presumed that interaction between WNV C and DDX56 would occur in both cellular compartments. However, recent data indicate that such interaction only occurs in the nucleus [77]. In contrast, a large proportion of cytoplasmic DDX56 colocalized with WNV E protein at the ER, suggesting that DDX56 indeed localizes to virus assembly sites. Nevertheless, how the CDDX56 and E-DDX56 nuclear and cytoplasmic interactions, affect the packaging of vRNA into virions remains unknown.

Nucleolin, a highly conserved nuclear phosphoprotein, is another RBP shown to mediate Flavivirus assembly [78]. Balinsky et al found that nucleolin interacts with DENV $\mathrm{C}$ in both nucleus and cytoplasm in an RNAindependent manner. The interaction, which was verified in DENV-infected cells as well as in cell-free reactions, was abolished by the use of a nucleolin-binding aptamer (AS1411). Furthermore, siRNA-mediated knockdown of nucleolin as well as treatment with AS1411 resulted in a significant decrease of DENV titers despite similar levels of intracellular vRNA and viral proteins and secreted E and $\mathrm{C}$. These results resemble those of DDX56, however, chemical interference of nucleolin slightly reduced the number of vRNA copies in supernatant and nucleolin knockdown did not affect secreted vRNA at all. The authors failed to investigate why siRNA-mediated knockdown of nucleolin resulted in lower virus titers without altering supernatant vRNA. It would be interesting to test whether the lost interactions between nucleolin and $\mathrm{C}$ increases the ratio of immature viruses, thus generating virus progeny with the same vRNA levels but with different infectivity.

Recently, our group uncovered two other RBPs that are required beyond the replication step of Flavivirus vRNA. One of them is Y-box-binding protein 1 (YBX1), a highly conserved cold shock domain protein that binds to DENV vRNA [38, 107, 108]. We previously reported that siRNA-mediated knockdown of YBX1 increased the intracellular DENV vRNA levels while the release of infectious particles was impaired, suggesting a role for YBX1 at the stages of assembly/secretion [108]. We have now expanded these findings and confirmed that CRISPR-Cas9-mediated knockout of YBX1 results in a significant decrease of infectious titers, vRNA and structural proteins in supernatants, whereas no changes in intracellular viral proteins are observed (Diosa-Toro et al, unpublished results). Currently, we hypothesize that assembly of infectious particles is impaired in cells lacking YBX1. The second protein complex affecting late steps is Topoisomerase 3B (Top3B)-Tudor Domain Containing protein 3 (TDRD3) complex. The Top3BTDRD3 is a dual activity complex that is essential for promoting both transcription and translation $[109,110]$. CRISPR/Cas9 based deletion of Top3B-TDRD3 complex components did not affect Flavivirus translation and replication, whereas it impaired the production of infectious virus particles. We further characterized that depletion of Top3B-TDRD3 complex did not inhibit particle release (Prasanth et al, unpublished results).

\section{Role of RBPs in determining the extracellular fate of RNA molecules}

Progeny virus particles are considered the sole mechanism for the dissemination of flaviviruses. Nevertheless, cell-derived extracellular vesicles carrying Flavivirus vRNA have recently been shown to be infectious [111$116]$, thus representing an alternate mode of virus dissemination. The pathway leading to the secretion of vRNA independently of virus particles is unknown, but parallels can be drawn with the export of cellular RNAs. In recent years, the literature has seen an explosion of studies on the extracellular RNA species that are found in supernatants from cultured cells and in extracellular compartments in vivo [117-119]. RNA is found outside cells as cargo of extracellular vesicles (EVs) or in tight association with RBPs and/or lipids [117]. EVs are heterogeneous in size, and include apoptotic bodies, microvesicles and exosomes. Microvesicles (100-1000 nm) bud from the plasma membrane, and exosomes (40-100 $\mathrm{nm})$ originate from the endocytic pathway [120]. In the latter, vesicles progress from early to late endosomes, where cargo is sequestered into intraluminal vesicles (ILVs) (Fig. 2). ILVs arise from the inward budding of the outer endosomal membrane, thus, forming a multivesicular body (MVB). MVBs either fuse with lysosomes for degradation or fuse with the plasma membrane in which case, the ILVs are released into the extracellular milieu as exosomes [121]. By transferring a wide range of molecules, such as proteins, RNAs and lipids, exosomes modulate intercellular communication during homeostatic and pathogenic conditions. For example, EVs from infected cells have been shown to harbour 


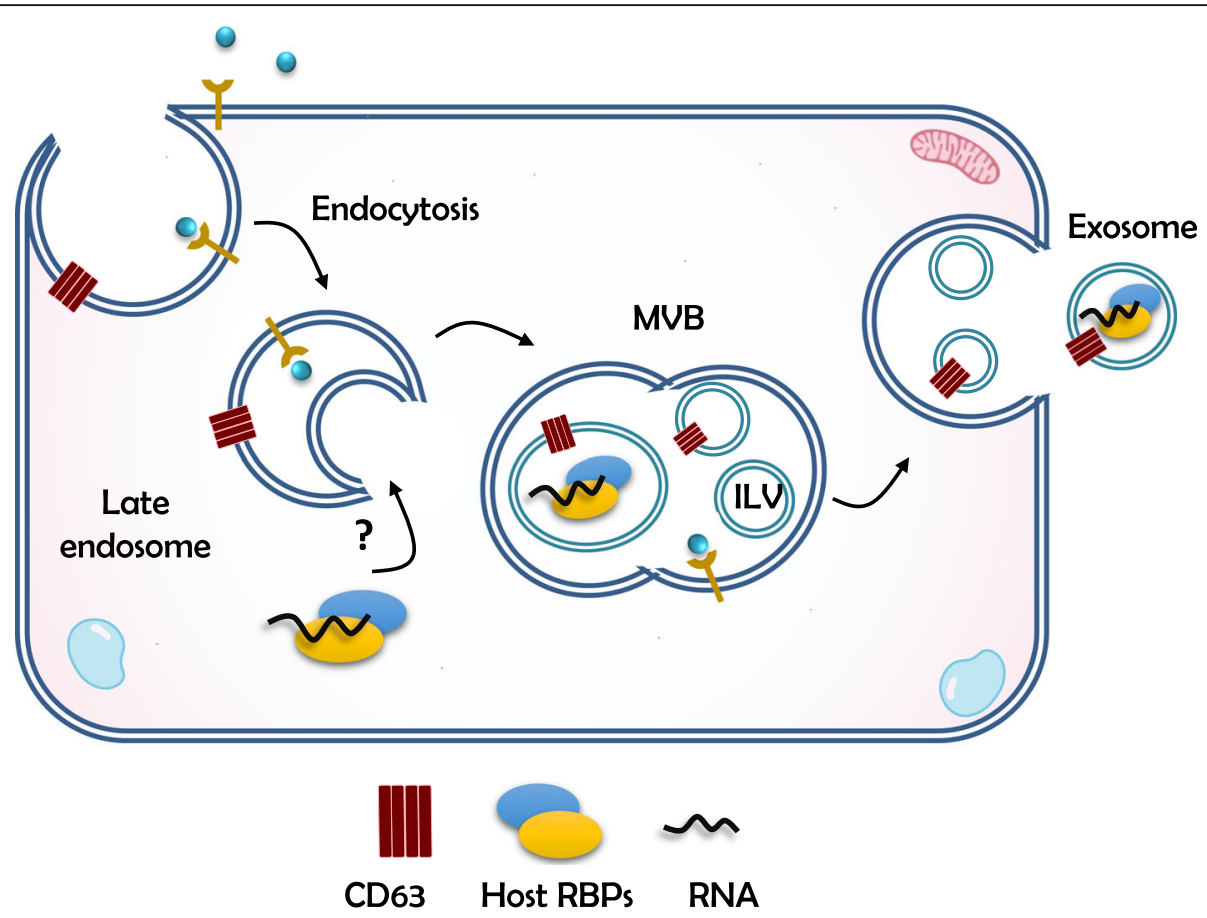

Fig. 2 Exosome biogenesis. Late endosomes sequester cargo molecules in intraluminal vesicles (ILVs) generating multivesicular bodies (MVBS). MVBs fuse with lysosomes for degradation or fuse with the plasma membrane releasing exosomes to the extracellular milieu. The intersection between cytoplasmic ribonucleoprotein complexes and endosomes might be a step prior the export of RNA molecules via exosomes

antiviral proteins such as APOBEC3G and STING [122, 123], indicating how immune signals can be transferred to elicit responses in neighbouring cells. On the other hand, EVs are also hijacked by viruses to facilitate dissemination.

Studies on extracellular RNAs have primarily focused on microRNAs (miRNAs), small (20-22 nucleotides) non-coding RNAs that target mRNAs and usually induce silencing of gene expression [124, 125]. Exosomeassociated miRNAs regulate multiple cellular processes within the recipient cells and are considered potential biomarkers for cancer and metabolic diseases [126-128]. Nevertheless, we lack understanding of the mechanisms that govern sorting of these RNA molecules into exosomes. Because exosomes are enriched in particular classes of RNAs and their content does not always reflect the intracellular RNA pool [129-132], a mechanism by which certain RNAs are selected as cargo for exosomes must be in place. Whether cis-acting regulatory sequences/structures on the RNA molecule or trans-acting factors - or both- are responsible for the export of RNAs remains largely unknown. Potential cis-acting factors are the short motifs GGAG and GGCU that were found enriched in exosomal miRNAs and were specifically recognized by heterogeneous nuclear ribonucleoprotein A2B1 (hnRNPA2B1) in human primary Tlymphocytes [133] and by hnRNP Q in hepatocytes [134]. Nevertheless, not all exosomal miRNAs contain those (or other) motifs. For example, despite lacking particular signals associated with exosomes, miR-223 was found to be specifically sorted into exosomes by YBX1 in HEK293T cells and in cell-free reactions [135]. Further evidence points towards a more general role of YBX1 in the sorting of other highly abundant types of small RNAs such as tRNAs, Y RNAs and Vault RNAs [132]. Because RBPs such as hnRNPA2B1, hnRNP Q and YBX1 do not contain transmembrane domains it remains unclear how they mediate interaction with MBVs. Interestingly, all these proteins localize to cytoplasmic RNP complexes [136-138] and it has been suggested that intersection between RNPs and MBVs is a required step prior to the secretion of RNA molecules [139]. Hence, determinants for secretion are likely cell specific and dependent on factors such as the binding affinity of certain RBPs for particular RNA molecules. Certainly, a wide range of RBPs are also found in exosomes [140], favouring a hypothesis in which RNP complexes carry the signals for secretion.

Besides carrying endogenous molecules, EVs also carry virus particles and infectious genomes. This phenomenon was initially discovered for non-enveloped viruses in which several viral genomes are packaged and released inside EVs, thus mediating en bloc viral transmission [141, 142]. Interestingly, several reports indicate that enveloped viruses that are traditionally seen to disseminate as free viral particles, also exploit EVs for their 
propagation [142] [143]. In particular, cells infected with HCV [144-146], DENV [111-114], ZIKV [115] and TBEV [116] release exosomes that are infectious to recipient cells. These infectious exosomes carry full-length vRNA but do not always contain the structural viral proteins associated with virions, thus suggesting that in Flavivirus-infected cells, vRNA molecules are sorted into exosomes independently of the assembly of fully mature particles. It is not known how vRNAs are sequestered into endosomal ILVs, but it is likely that, as in the case of cellular RNAs, specific RBPs would mediate the interaction with MBVs. For example, exosomes from sera of HCV-infected patients were found to contain vRNA, miR-122, HSP90 and the RBP Ago2 [145]. The binding of miR-122 to HCV vRNA in association with Ago2 favors vRNA replication $[147,148]$ and it was previously shown that HSP90 functions as a chaperone for Argonaute proteins facilitating the loading of small RNAs [149]. It is interesting that these components of cytoplasmic RNPs are present in infectious HCV exosomes. Similarly, it is intriguing that YBX1 and hnRNPA2B1, previously described to mediate the packaging of cellular RNAs into exosomes, have been shown to bind DENV vRNA [107, 108, 150]. Furthermore, DENV, WNV and TBEV vRNA colocalizes with several RBPs present in cytoplasmic RNA granules [35, 151-154], which could potentially facilitate its sorting into exosomes. Collectively, these data highlight a previously overlooked function of cellular RBPs during Flavivirus infection. We propose that these proteins do not only favor the assembly and release of traditional virions, but are likely involved in the secretion of alternative infectious units, with potentially important consequences for viral dissemination and immune recognition.

\section{Conclusions}

The remarkable multifunctionally of the viral-encoded RBPs and the large diversity of the host RBPs co-opted by flaviviruses highlights the importance of these proteins in determining virus-cell host interactions. Here, we emphasize that in addition to the better characterized functions during vRNA translation and replication, RBPs participate at later stages of the Flavivirus replication cycle, particularly, during the packaging of vRNA and assembly into virus particles. Furthermore, we propose that the biogenesis of infectious exosomes, which represent an alternate mode of virus dissemination, relies on the recognition of vRNA by host RBPs (Fig. 3).

In Flavivirus-infected cells, newly synthesized RNA is translated to generate new viral proteins, as template to generate additional vRNA molecules, as precursor of sfRNA molecules and is encapsidated into new virus

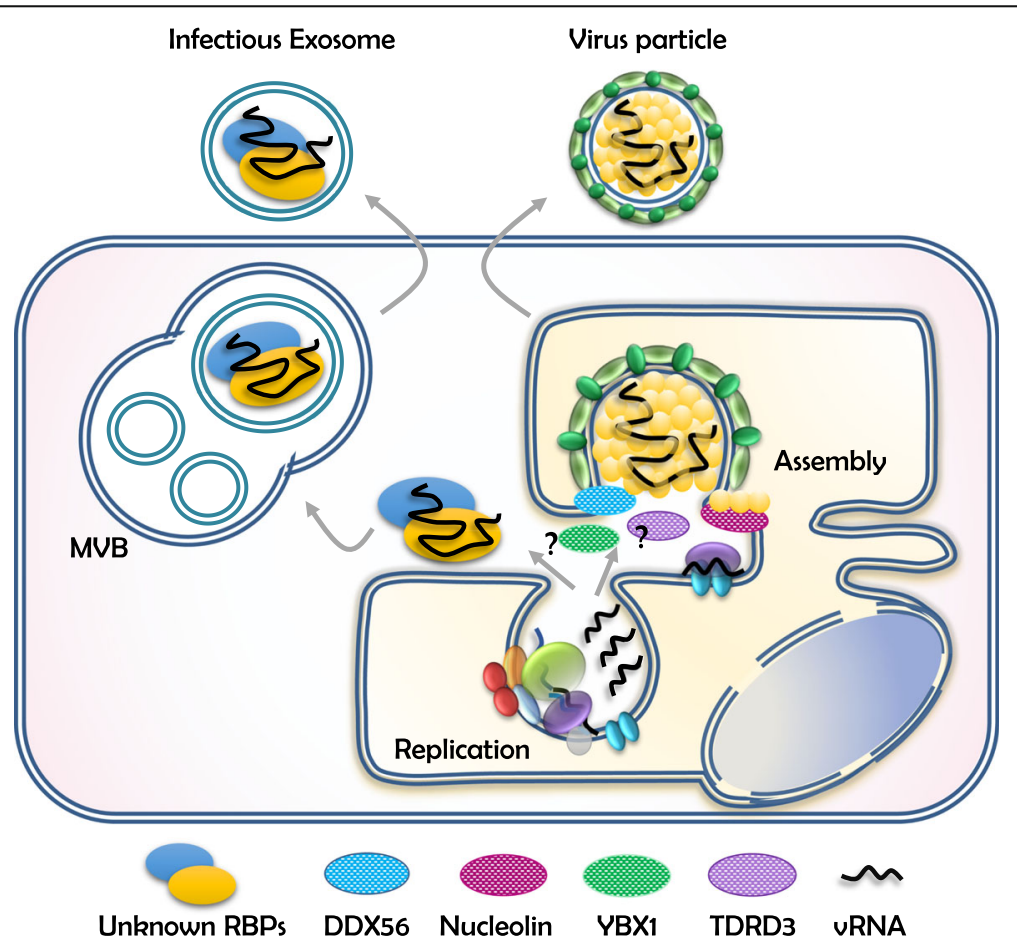

Fig. 3 Cellular RBPs participate in the assembly of Flavivirus particles and possibly the loading of vRNA into exosomes. In addition to viralencoded proteins (Fig. 2), host RBPs including DDX56 and nucleolin have been reported to enable Flavivirus assembly. Furthermore, our group has discovered that YBX1 and TDRD3 are also required during this step (unpublished results). We propose that RBPs also mediate the sorting of VRNA into exosomes and therefore contribute to an alternative route of virus dissemination 
particles. How does the virus coordinates these processes remains largely unknown. The process of assembly is considered highly specific because only positive-sense vRNA molecules are incorporated into budding virions. Remarkably, this is a common assumption that requires experimental verification. Whereas the coupling of replication and assembly confers specificity to vRNA (thus, excluding cellular RNA molecules from being incorporated into virus particles), how negative-sense RNA and sfRNA molecules are excluded from the assembly process remains to be determined. We have to consider, however, that the exclusion of sfRNA from virions, which was reported by our group for DENV2-NGC [35], may not be conserved for all flaviviruses. It is likely that dynamic secondary and tertiary structures adopted by the vRNA at different stages of the replication cycle will affect its interaction with viral proteins and cellular RBPs, thus conferring molecular specificity for different processes. Interestingly, we also lack evidence to confirm another widespread assumption about the protein composition of flaviviruses particles, that is, that only $\mathrm{C}$, $\mathrm{prM} / \mathrm{M}$ and $\mathrm{E}$ are present. Given the critical role of NS2A and NS3 during virus assembly that we summarize in this review, it remains a possibility that these viral RBPs are incorporated into virions. Indeed, the interior structure and composition of Flavivirus particles remains elusive and, to the best of our knowledge, proteomic analysis of virus preparations are lacking. For the same reason, host proteins have not been associated with Flavivirus virions unlike the related HCV particles, which incorporate host apolipoproteins $[155,156]$.

Remarkably, host RBPs potentially contribute to the dissemination of Flavivirus infection via the incorporation of vRNA into exosomes. How these infectious exosomes are formed and what they contribute to viral dissemination is not known. Taking into account that exosomes may be poorly recognized by the host immune system [157] and that en bloc transmission of multiple genomes favors higher replicative fitness [141, 142], a deeper study of the role of exosomes during Flavivirus infection and their biogenesis is warranted. It is interesting that viral assembly/release and exosome biogenesis share common features, such as membrane remodelling, loading of specific cargo and fusion with the plasma membrane. Furthermore, host factors from the vesicular trafficking machinery are required for the egress of flaviviruses. For example, the assembly, but not replication, of DENV, JEV and YFV has been shown to require components of ESCRT, which is central to exosome biogenesis [102, 104]. In addition, DENV, WNV and ZIKV have been shown to induce autophagy [158-162], a pathway that was recently described to mediate the loading of RBPs into EVs [163]. Further studies are required to establish whether flaviviruses evolved to co-opt exosomes as an alternative route of dissemination, but it is clear that RBPs guide the fate of vRNA molecules and thus, potentially determine the mechanism by which viral infection is disseminated.

\begin{abstract}
Abbreviations
ALIX: Apoptosis linked gene-2-interacting protein X; C: Capsid; CD: Cluster of differentiation; CLEC5A: C-type lectin domain family 5 member A;

CS: Complementary sequence; DB: Dumbbell; DDX56: DEAD-box helicase 56; DENV: Dengue virus; dsRNA: Double stranded RNA; E: Envelope;

ER: Endoplasmic reticulum; ESCRT: Endosomal sorting complex required for transport; EVs: Extracellular vesicles; HCV: Hepatitis C virus;

hnRNP: Heterogeneous nuclear ribonucleoprotein; ILV: Intraluminal vesicle; JEV: Japanese encephalitis virus; KUN: Kunjin; M: Membrane; miRNAs: micro RNA; MVB: Multivesicular body; NMD: Non-sense mediated decay; NS: Nonstructural protein; ORF: Open reading frame; pTMS: predicted

transmembrane segments; RdRp: RNA-dependent RNA polymerase; RNP: Ribonucleoprotein complex; sfRNA: subgenomic flaviviral RNA; SL: Stemloop; TAM: Tyro3, Axl, and Mer; TBEV: Tick-borne encephalitis virus;

TDRD3: Tudor Domain Containing 3; TIM/TAM: T-cell immunoglobulin and mucin domain 1; TMs: Transmembrane domains; VP: Vesicle packets; VRNA: viral RNA; WNV: West Nile virus; xrRNA: exonuclease resistant RNA structure; YBX1: Y-box-binding protein 1; YFV: Yellow fever virus; ZIKV: Zika virus
\end{abstract}

\section{Acknowledgements}

Not applicable.

\section{Authors' contributions}

MDT, KRP, SB and MGB conceptualized and wrote the manuscript. All authors read and approved the final manuscript.

\section{Funding}

MDT is recipient of a Rubicon Fellowship from the Dutch Research Council (NWO). The group in Singapore acknowledges funding from the Duke-NUS Medical School Signature Research Programme funded by the Agency for Science, Technology and Research (A*STAR), Singapore, and the Ministry of Health, Singapore (MAGB). The group in Galveston acknowledges funding from the University of Texas Medical Branch (MAGB).

\section{Availability of data and materials \\ Not applicable.}

Ethics approval and consent to participate

Not applicable.

\section{Consent for publication}

Not applicable.

\section{Competing interests}

The authors declare that they have no competing interests.

\section{Author details \\ 'Programme in Emerging Infectious Diseases, Duke-NUS Medical School, Singapore, Singapore. ${ }^{2}$ Department of Biochemistry and Molecular Biology, University of Texas Medical Branch, Galveston, TX, USA. ${ }^{3}$ Global Health, Surveillance \& Diagnostics Group, MRIGlobal, Kansas City, MO, USA. ${ }^{4}$ Institute for Human Infections and Immunity, University of Texas Medical Branch, Galveston, TX, USA.}

Received: 5 February 2020 Accepted: 11 April 2020

Published online: 25 April 2020

\section{References}

1. Finlay C. The Mosquito Hypothetically Considered as an Agent in the Transmission of Yellow Fever Poison. Yale J Biol Med. 1937;9(6):589-604 Available from: http://www.ncbi.nlm.nih.gov/pubmed/31693803. 
2. Reed W, Carroll J, Agramonte A. The etiology of yellow fever: An additional note. J Am Med Assoc. 1901;XXXVI(7):431-40.

3. Reed W, Carroll J. Yellow fever : 100 years of discovery The etiology of yellow fever : an additional note. JAMA Class. 2008;36(8):1-3.

4. Blitvich BJ, Firth AE. Insect-specific flaviviruses: A systematic review of their discovery, host range, mode of transmission, superinfection exclusion potential and genomic organization. Viruses. 2015;7:1927-59.

5. Villordo SM, Carballeda JM, Filomatori CV, Gamarnik AV. RNA Structure Duplications and Flavivirus Host Adaptation. Trends Microbiol. 2016;24(4): 270-83 Available from: http://www.ncbi.nlm.nih.gov/pubmed/26850219.

6. Gould EA, Solomon T. Pathogenic flaviviruses. Lancet. 2008;371(9611):500-9 Available from: http://www.ncbi.nlm.nih.gov/pubmed/18262042.

7. Bhatt S, Gething PW, Brady OJ, Messina JP, Farlow AW, Moyes $\mathrm{CL}$, et al. The global distribution and burden of dengue. Nature. 2013;496(7446):504-7 Available from: http://www.ncbi.nlm.nih.gov/pubmed/23563266. Cited 2013 Oct 18.

8. Moyes CL, Vontas J, Martins AJ, Ng LC, Koou SY, Dusfour I, et al. Contemporary status of insecticide resistance in the major Aedes vectors of arboviruses infecting humans. PLoS Negl Trop Dis. 2017;11(7):1-20.

9. Achee NL, Grieco JP, Vatandoost H, Seixas G, Pinto J, Ching-Ng L, et al. Alternative strategies for mosquito-borne arbovirus control. PLoS Negl Trop Dis. 2019;13(1):e0006822 Available from: http://www.ncbi.nlm.nih.gov/ pubmed/30605475.

10. Barrett $A D$, Teuwen $D E$. Yellow fever vaccine - how does it work and why do rare cases of serious adverse events take place? Curr Opin Immunol. 2009;21(3):308-13.

11. Halstead SB, Thomas SJ. Japanese encephalitis: new options for active immunization. Clin Infect Dis. 2010;50(8):1155-64 Available from: http:// www.ncbi.nlm.nih.gov/pubmed/20218889. cited 2013 Sep 25.

12. Heinz FX, Holzmann H, Essl A, Kundi M. Field effectiveness of vaccination against tick-borne encephalitis. Vaccine. 2007;25(43):7559-67.

13. Halstead SB. Critique of World Health Organization Recommendation of a Dengue Vaccine. J Infect Dis. 2016;214:jiw340. Available from:. https://doi. org/10.1093/infdis/jiw340.

14. Sridhar S, Luedtke A, Langevin E, Zhu M, Bonaparte M, Machabert T, et al. Effect of dengue serostatus on dengue vaccine safety and efficacy. N Engl J Med. 2018;379(4):327-40.

15. Biswal S, Reynales H, Saez-Llorens X, Lopez P, Borja-Tabora C, Kosalaraksa P, et al. Efficacy of a tetravalent dengue vaccine in healthy children and adolescents. N Engl J Med. 2019:2009-19 Available from: http://www.ncbi. nlm.nih.gov/pubmed/31693803.

16. Counotte MJ, Egli-Gany D, Riesen M, Abraha M, Porgo TV, Wang J, et al. Zika virus infection as a cause of congenital brain abnormalities and Guillain-Barré syndrome: From systematic review to living systematic review [version 1; referees: 2 approved, 1 approved with reservations]. F1000Res. 2018;7:196. https://doi.org/10.12688/f1000research. https://www.ncbi.nlm.nih.gov/ pubmed/30631437.

17. Kuhn RJ, Zhang W, Rossmann MG, Pletnev SV, Corver J, Lenches E, et al. Structure of dengue virus: implications for flavivirus organization, maturation, and fusion. Cell. 2002;108(5):717-25 Available from: http://www. ncbi.nlm.nih.gov/pubmed/11893341.

18. Li L, Lok S-M, Yu I, Zhang Y, Kuhn RJ, Chen J, et al. The Flavivirus Precursor Membrane-Envelope Protein Complex: Structure and Maturation. Science (80- ). 2008;319(March):1830-5.

19. Yu I, Zhang W, Holdaway HA, Li L, Kostyuchenko VA, Chipman PR, et al. Structure of the Immature Dengue Virus at Low pH Primes Proteolytic Maturation. Science (80- ). 2008;319(5871):1834-7.

20. Smith TJ, Brandt WE, Swanson JL, McCown JM, Buescher EL. Physical and biological properties of dengue-2 virus and associated antigens. J Virol. 1970;5(4):524-32.

21. Ray D, Shah A, Tilgner M, Guo Y, Zhao Y, Dong H, et al. West Nile virus 5'cap structure is formed by sequential guanine $\mathrm{N}-7$ and ribose 2'-O methylations by nonstructural protein 5. J Virol. 2006;80(17):8362-70 Available from: https://www.pubmedcentral.nih.gov/articlerender.fcgi?artid= 1563844\&tool=pmcentrez\&rendertype=abstract. Cited 2013 Oct 3.

22. Brinton MA, Fernandez AV, Dispoto JH. The 3'-nucleotides of flavivirus genomic RNA form a conserved secondary structure. Virology. 1986;153(1): 113-21.

23. Filomatori CV, Lodeiro MF, Alvarez DE, Samsa MM, Pietrasanta L, Gamarnik AV. A 5 RNA element promotes dengue virus RNA synthesis on a circular genome. Genes Dev. 2006;20:2238-49.
24. Gebhard LG, Filomatori CV, Gamarnik AV. Functional RNA elements in the denque virus genome. Viruses. 2011;3(9):1739-56 Available from: http:// www.pubmedcentral.nih.gov/articlerender.fcgi?artid=3187688\&tool= pmcentrez\&rendertype=abstract. Cited 2013 Sep 25.

25. Basu A, Chaturvedi UC. Vascular endothelium: the battlefield of dengue viruses. FEMS Immunol Med Microbiol. 2008;53(3):287-99 Available from: http://www.ncbi.nlm.nih.gov/pubmed/18522648. Cited 2013 Oct 17.

26. Bredenbeek PJ. A stable full-length yellow fever virus CDNA clone and the role of conserved RNA elements in flavivirus replication. J Gen Virol. 2003; 84(5):1261-8. Available from:. https://doi.org/10.1099/vir.0.18860-0.

27. Lo MK, Tilgner M, Bernard KA, Shi P-Y. Functional analysis of mosquitoborne Flavivirus conserved sequence elements within 3' Untranslated region of West Nile virus by use of a reporting replicon that differentiates between viral translation and RNA replication. J Virol. 2003;77(18):10004-14. Available from:. https://doi.org/10.1128/JVI.77.18.10004-10014.2003.

28. Hahn CS, Hahn YS, Rice CM, Lee E, Dalgarno L, Strauss EG, et al. Conserved elements in the $3^{\prime}$ untranslated region of flavivirus RNAs and potential cyclization sequences. J Mol Biol. 1987;198(1):33-41.

29. Pijlman GP, Funk A, Kondratieva N, Leung J, Torres $S$, van der Aa L, et al. A highly structured, nuclease-resistant, noncoding RNA produced by flaviviruses is required for pathogenicity. Cell Host Microbe. 2008;4(6):579-91 Available from: http://www.ncbi.nlm.nih.gov/pubmed/19064258. Cited 2013 Sep 25.

30. Chapman EG, Costantino DA, Rabe JL, Moon SL, Wilusz J, Nix JC, et al. The structural basis of pathogenic subgenomic flavivirus RNA (sfRNA) production. Science (80- ). 2014;344(6181):307-10.

31. Funk A, Truong K, Nagasaki T, Torres S, Floden N, Balmori Melian E, et al. RNA structures required for production of subgenomic flavivirus RNA. J Virol. 2010;84(21):11407-17.

32. Kieft JS, Rabe JL, Chapman EG. New hypotheses derived from the structure of a flaviviral Xrn1-resistant RNA: conservation, folding, and host adaptation. RNA Biol. 2015;12(11):1117-69.

33. MacFadden A, Odonoghue Z, Silva PAGC, Chapman EG, Olsthoorn RC, Sterken MG, et al. Mechanism and structural diversity of exoribonucleaseresistant RNA structures in flaviviral RNAs. Nat Commun. 2018;9(1):1-11. Available from:. https://doi.org/10.1038/s41467-017-02604-y.

34. Slonchak A, Khromykh AA. Subgenomic flaviviral RNAs: what do we know after the first decade of research. Antivir Res. 2018;159(August):13-25.

35. Bidet K, Dadlani D, Garcia-Blanco MA. G3BP1, G3BP2 and CAPRIN1 Are Required for Translation of Interferon Stimulated mRNAs and Are Targeted by a Dengue Virus Non-coding RNA. PLoS Pathog. 2014;10(7):e1004242. https://doi.org/10.1371/journal.ppat.1004242. https://www.ncbi.nlm.nih.gov/ pubmed/24992036.

36. Schuessler A, Funk A, Lazear HM, Cooper D a, Torres S, Daffis S, et al. West Nile virus noncoding subgenomic RNA contributes to viral evasion of the type I interferon-mediated antiviral response. J Virol [Internet]. 2012 May [cited 2015 Jan 12];86(10):5708-18. Available from: http://www. pubmedcentral.nih.gov/articlerender.fcgi?artid=3347305\&tool= pmcentrez\&rendertype $=$ abstract.

37. Pompon J, Manuel M, Ng GK, Wong B, Shan C, Manokaran G, et al. Dengue subgenomic flaviviral RNA disrupts immunity in mosquito salivary glands to increase virus transmission. PLoS Pathog. 2017;13(7):e1006535.

38. Manokaran G, Finol E, Wang C, Gunaratne J, Bahl J, Ong EZ, et al. Dengue subgenomic RNA binds TRIM25 to inhibit interferon expression for epidemiological fitness. Science (80- ). 2015;350(6257):217-21.

39. Laureti M, Narayanan D, Rodriguez-Andres J, Fazakerley JK, Kedzierski L. Flavivirus receptors: diversity, identity, and Cell entry. Front Immunol. 2018; 9(September):2180.

40. Cruz-Oliveira C, Freire JM, Conceição TM, Higa LM, Castanho MARB, Da Poian AT. Receptors and routes of dengue virus entry into the host cells. FEMS Microbiol Rev. 2015;39(2):155-70.

41. Meertens L, Carnec X, Lecoin MP, Ramdasi R, Guivel-Benhassine F, Lew E, et al. The TIM and TAM families of phosphatidylserine receptors mediate dengue virus entry. Cell Host Microbe. 2012;12(4):544-57.

42. Halstead SB. Antibody-enhanced dengue virus infection in primate leukocytes. Nature. 1977;265:739-41.

43. Chu JJH, Ng ML. Infectious entry of West Nile virus occurs through a clathrin-mediated endocytic pathway. J Virol. 2004;78(19):10543-55 Available from: http://www.ncbi.nlm.nih.gov/pubmed/15367621.

44. van der Schaar HM, Rust MJ, Waarts B-L, van der Ende-Metselaar H, Kuhn RJ, Wilschut J, et al. Characterization of the early events in dengue virus cell entry by biochemical assays and single-virus tracking. J Virol. 2007;81 (21):12019-28. 
45. Zaitseva E, Yang ST, Melikov K, Pourmal S, Chernomordik LV. Dengue virus ensures its fusion in late endosomes using compartment-specific lipids. PLoS Pathog. 2010;6(10):e1001131.

46. Byk LA, Iglesias NG, De Maio FA, Gebhard LG, Rossi M, Gamarnik AV. Dengue virus genome Uncoating requires Ubiquitination. MBio. 2016; 7(3):1-10.

47. Garcia-Blanco MA, Vasudevan SG, Bradrick SS, Nicchitta C. Flavivirus RNA transactions from viral entry to genome replication. Antiviral Res. 2016;134: 244-9 Elsevier B.V.

48. Reid DW, Campos RK, Child JR, Zheng T, Chan KWK, Bradrick SS, et al. Dengue virus selectively annexes endoplasmic reticulum-Associated translation machinery as a strategy for co-opting Host Cell Protein synthesis. J Virol. 2018;92(7). https://doi.org/10.1128/JVI.01766-17. https://www.ncbi. nlm.nih.gov/pubmed/29321322.

49. Jackson RJ, Hellen CUT, Pestova TV, et al. Nat Rev Mol Cell Biol. 2010;11(2): 113-27. Available from:. https://doi.org/10.1038/nrm2838.

50. Edgil D, Polacek C, Harris E. Dengue virus utilizes a novel strategy for translation initiation when cap-dependent translation is inhibited. Society. 2006;80(6):2976-86.

51. Villas-Bôas CSA, Conceição TM, Ramírez J, Santoro ABM, Da Poian AT, Montero-Lomelí $\mathrm{M}$. Dengue virus-induced regulation of the host cell translational machinery. Brazilian J Med Biol Res. 2009;42(11):1020-6.

52. Roth $H$, Magg V, Uch F, Mutz P, Klein P, Haneke K, et al. Flavivirus infection uncouples translation suppression from cellular stress responses. MBio. 2017; 8(1):e02150-16. Available from: https://doi.org/10.1128/mBio.02150-16.

53. Rice CM, Lenches EM, Eddy SR, Shin SJ, Sheets RL, Strauss JH. Nucleotide sequence of yellow fever virus: implications for flavivirus gene expression and evolution. Science. 1985;229(4715):726-33 Available from: http://www. ncbi.nlm.nih.gov/pubmed/4023707.

54. Chambers TJ, Hahn CS, Galler R, Rice CM. Flavivirus genome organization, expression and replication. Rev Microbiol. 1990;44:649-88.

55. Welsch S, Miller S, Romero-Brey I, Merz A, Bleck CKE, Walther P, et al. Composition and three-dimensional architecture of the dengue virus replication and assembly sites. Cell Host Microbe. 2009;5(4):365-75 Available from: http://www.ncbi.nlm.nih.gov/pubmed/19380115. Cited 2013 Nov 7.

56. Mackenzie J. Wrapping things up about virus RNA replication. Traffic. 2005; 6(11):967-77.

57. Barrows NJ, Campos RK, Liao KC, Prasanth KR, Soto-Acosta R, Yeh SC, et al. Biochemistry and molecular biology of Flaviviruses. Chem Rev. 2018;118(8): 4448-82.

58. Mazeaud C, Freppel W, Chatel-Chaix L. The multiples fates of the Flavivirus RNA genome during pathogenesis. Front Genet. 2018;9:595.

59. Stadler K, Allison SL, Schalich J, Heinz FX. Proteolytic activation of tick-borne encephalitis virus by furin. J Virol. 1997;71(11):8475-81 Available from: http:// www.ncbi.nlm.nih.gov/pubmed/9343204\%0A. http://www.pubmedcentral. nih.gov/articlerender.fcgi?artid=PMC192310.

60. Wengler G, Wengler G. Cell-associated West Nile flavivirus is covered with $\mathrm{E}+$ pre-M protein heterodimers which are destroyed and reorganized by proteolytic cleavage during virus release. J Virol. 1989; 63(6):2521-6

61. Russell PK, Brandt WE, Dalrymple JM. Chemical and Antigenic Structure of Flaviviruses. The Togaviruses: Biology, structure and replication. Cambridge: Academic Press, Inc.; 1980. p. 503-29. https://doi.org/10.1016/b978-0-12625380-1.50023-0. https://www.sciencedirect.com/science/article/pii/ B9780126253801500230?via\%3Dihub.

62. Stockley PG, Twarock R, Bakker SE, Barker AM, Borodavka A, Dykeman E, et al. Packaging signals in single-stranded RNA viruses: Nature's alternative to a purely electrostatic assembly mechanism. J Biol Phys. 2013;39(2):277-87.

63. Pong WL, Huang ZS, Teoh PG, Wang CC, Wu HN. RNA binding property and RNA chaperone activity of dengue virus core protein and other viral RNAinteracting proteins. FEBS Lett. 2011;585(16):2575-81. Available from:. https://doi.org/10.1016/j.febslet.2011.06.038.

64. Byk LA, Gamarnik AV. Properties and functions of the dengue virus capsid Protein. Annu Rev Virol. 2016;(July):1-19 Available from: http://www.ncbi. nlm.nih.gov/pubmed/27501261.

65. Samsa MM, Mondotte JA, Caramelo JJ, Gamarnik AV. Uncoupling cis-acting RNA elements from coding sequences revealed a requirement of the $\mathrm{N}$ terminal region of dengue virus capsid Protein in virus particle formation. J Virol. 2012;86(2):1046-58.
66. Zhang W, Chipman PR, Corver J, Johnson PR, Zhang Y, Mukhopadhyay S, et al. Visualization of membrane protein domains by cryo-electron microscopy of dengue virus. Nat Struct Biol. 2003;10(11):907-12.

67. Zhang Y, Kostyuchenko VA, Rossmann MG. Structural analysis of viral nucleocapsids by subtraction of partial projections. J Struct Biol. 2007; 157(2):356-64.

68. Khromykh AA, Varnavski AN, Sedlak PL, Westaway EG. Coupling between replication and packaging of Flavivirus RNA: evidence derived from the use of DNA-based full-length cDNA clones of Kunjin virus. J Virol. 2001;75(10): 4633-40.

69. Gokhale NS, McIntyre ABR, McFadden MJ, Roder AE, Kennedy EM, Gandara JA, et al. N6-Methyladenosine in Flaviviridae viral RNA genomes regulates infection. Cell Host Microbe. 2016;20(5):654-65. Available from: https://doi. org/10.1016/j.chom.2016.09.015.

70. Li M, Johnson JR, Truong B, Kim G, Weinbren N, Dittmar M, et al. Identification of antiviral roles for the exon-junction complex and nonsense-mediated decay in flaviviral infection. Nat Microbiol. 2019;4(6): 985-95.

71. Katoh H, Okamoto T, Fukuhara T, Kambara H, Morita E, Mori Y, et al. Japanese encephalitis virus Core Protein inhibits stress granule formation through an interaction with Caprin-1 and facilitates viral propagation. J Virol. 2012;87(1):489-502.

72. Tsuda Y, Mori Y, Abe T, Yamashita T, Okamoto T, Ichimura T, et al. Nucleolar protein B23 interacts with Japanese encephalitis virus core protein and participates in viral replication. Microbiol Immunol. 2006; 50(3):225-34.

73. Chang CJ, Luh HW, Wang SH, Lin HJ, Lee SC, Hu ST. The heterogeneous nuclear ribonucleoprotein $\mathrm{K}(\mathrm{hnRNP} \mathrm{K})$ interacts with dengue virus core protein. DNA Cell Biol. 2001;20(9):569-77.

74. Zhang Q, Rodriguez-lado L, Liu J, Johnson CA, Zheng Q, Sun G. The heterogeneous nuclear ribonucleoprotein $\mathrm{K}$ (hnRNPK) is a host factor required for dengue virus and Junin virus multiplication. Virus Res. 2013;203: 84-91. Available from: https://doi.org/10.1016/j.jhazmat.2013.02.017.

75. Xu Z, Anderson R, Hobman TC. The capsid-binding Nucleolar helicase DDX56 is important for infectivity of West Nile virus. J Virol. 2011;85(11): 5571-80.

76. Xu Z, Hobman TC. The helicase activity of DDX56 is required for its role in assembly of infectious West Nile virus particles. Virology. 2012:433(1):226-35. Available from:. https://doi.org/10.1016/j.virol.2012.08.011.

77. Reid CR, Hobman TC. The nucleolar helicase DDX56 redistributes to West Nile virus assembly sites. Virology. 2017;500(October 2016):169-77. Available from: https://doi.org/10.1016/j.virol.2016.10.025.

78. Balinsky CA, Schmeisser H, Ganesan S, Singh K, Pierson TC, Zoon KC. Nucleolin interacts with the dengue virus capsid Protein and plays a role in formation of infectious virus particles. J Virol. 2013;87(24):13094-106.

79. Murray $\mathrm{CL}$, Jones $\mathrm{CT}$, Rice CM. Architects of assembly: roles of Flaviviridae non-structural proteins in virion morphogenesis. Nat Rev Microbiol. 2008; 6(9):699-708.

80. Preugschat F, Yao CW, Strauss JH. In vitro processing of dengue virus type 2 nonstructural proteins NS2A, NS2B, and NS3. J Virol. 1990;64(9):4364-74.

81. Xie X, Gayen S, Kang C, Yuan Z, Shi P-Y. Membrane topology and function of dengue virus NS2A Protein. J Virol. 2013;87(8):4609-22.

82. Kummerer BM, Rice CM. Mutations in the yellow fever virus nonstructural Protein NS2A selectively block production of infectious particles. J Virol. 2002;76(10):4773-84

83. Voßmann S, Wieseler J, Kerber R, Kümmerer BM. A basic cluster in the $\mathrm{N}$ terminus of yellow fever virus NS2A contributes to infectious particle production. J Virol. 2015;89(9):4951-65.

84. Liu WJ, Chen HB, Khromykh AA. Molecular and functional analyses of Kunjin virus infectious CDNA clones demonstrate the essential roles for NS2A in virus assembly and for a nonconservative residue in NS3 in RNA replication. J Virol. 2003;77(14):7804-13.

85. Leung JY, Pijlman GP, Kondratieva N, Hyde J, Mackenzie JM, Khromykh AA. Role of nonstructural Protein NS2A in Flavivirus assembly. J Virol. 2008; 82(10):4731-41.

86. Xie X, Zou J, Puttikhunt C, Yuan Z, Shi P-Y. Two distinct sets of NS2A molecules are responsible for dengue virus RNA synthesis and Virion assembly. J Virol. 2015;89(2):1298-313.

87. Xie X, Zou J, Zhang X, Zhou Y, Routh AL, Kang C, et al. Dengue NS2A Protein orchestrates virus assembly. Cell Host Microbe. 2019;26(5):606-622. e8. Available from. https://doi.org/10.1016/j.chom.2019.09.015. 
88. Zhang X, Xie X, Xia H, Zou J, Huang L, Popov VL, et al. Zika virus NS2Amediated Virion assembly. MBio. 2019;10(5):1-21.

89. Shrivastava G, García-Cordero J, León-Juárez M, Oza G, Tapia-Ramírez J, Villegas-Sepulveda N, et al. NS2A comprises a putative viroporin of dengue virus 2. Virulence. 2017;8(7):1450-6.

90. Carrasco L. Modification of membrane permeability by animal viruses. Adv Virus Res. 1995;45(C):61-112.

91. Chang YS, Liao CL, Tsao CH, Chen MC, Liu Cl, Chen LK, et al. Membrane permeabilization by small hydrophobic nonstructural proteins of Japanese encephalitis virus. J Virol. 1999;73(8):6257-64 Available from: http://www. ncbi.nlm.nih.gov/pubmed/10400716\%0A. http://www.pubmedcentral.nih. gov/articlerender.fcgi?artid=PMC112703.

92. Urcuqui-inchima S, Patin C, DI FJ. Recent developments in understanding dengue virus replication. Adv Virus Res. 2010;77(10):1-39.

93. Gebhard LG, Kaufman SB, Gamarnik AV. Novel ATP-Independent RNA Annealing Activity of the Dengue Virus NS3 Helicase. Marcello A, editor. PLoS One. 2012;7(4):e36244. Available from:. https://doi.org/10.1371/journal. pone.0036244.

94. Li K, Phoo WW, Luo D. Functional interplay among the flavivirus NS3 protease, helicase, and cofactors. Virol Sin. 2014;29(2):74-85.

95. Lobigs M. Flavivirus premembrane protein cleavage and spike heterodime secretion require the function of the viral proteinase NS3. Proc Natl Acad Sci U S A. 1993;90(13):6218-22. Available from: http://www.ncbi.nlm.nih.gov/ pubmed/8392191.

96. Amberg SM, Rice CM. Mutagenesis of the NS2B-NS3-mediated cleavage site in the flavivirus capsid protein demonstrates a requirement for coordinated processing. J Virol. 1999;73(10):8083-94 Available from: http://www.ncbi.nlm. nih.gov/pubmed/10482557.

97. Pijlman GP, Kondratieva N, Khromykh AA. Translation of the Flavivirus Kunjin NS3 Gene in cis but not its RNA sequence or secondary Structure is essential for efficient RNA packaging. J Virol. 2006;80(22):11255-64.

98. Patkar CG, Kuhn RJ. Yellow fever virus NS3 plays an essential role in virus assembly independent of its known enzymatic functions. J Virol. 2008;82(7): 3342-52.

99. Swarbrick CMD, Basavannacharya C, Chan KWK, Chan SA, Singh D, Wei N, et al. NS3 helicase from dengue virus specifically recognizes viral RNA sequence to ensure optimal replication. Nucleic Acids Res. 2017:45(22): 12904-20.

100. Le Breton M, Meyniel-Schicklin L, Deloire A, Coutard B, Canard B, De Lamballerie $X$, et al. Flavivirus NS3 and NS5 proteins interaction network: A high-throughput yeast two-hybrid screen. BMC Microbiol. 2011;11:234

101. Carpp LN, Galler R, Bonaldo MC. Interaction between the yellow fever virus nonstructural protein NS3 and the host protein Alix contributes to the release of infectious particles. Microbes Infect. 2011;13(1):85-95. Available from: https://doi.org/10.1016/j.micinf.2010.10.010.

102. Thepparit C, Khongwichit S, Ketsuwan K, Libsittikul S, Auewarakul P, Smith DR. Dengue virus requires apoptosis linked gene-2-interacting protein $X$ (ALIX) for viral propagation. Virus Res. 2019;261:65-71.

103. Schmidt O, Teis D. The ESCRT machinery. Curr Biol [Internet]. 2012;22(4): R116-20. Available from:. https://doi.org/10.1016/j.cub.2012.01.028.

104. Tabata K, Arimoto M, Arakawa M, Nara A, Saito K, Omori H, et al. Unique requirement for ESCRT factors in Flavivirus particle formation on the endoplasmic reticulum. Cell Rep. 2016;16(9):2339-47.

105. Campos RK, Garcia-Blanco MA, Bradrick SS. Roles of Pro-viral Host Factors in Mosquito-Borne Flavivirus Infections. In: Tripp R, Tompkins S. (eds) Roles of Host Gene and Non-coding RNA Expression in Virus Infection. Curr Top Microbiol Immunol vol 419. Cham: Springer; 2017.

106. Zirwes RF, Eilbracht J, Kneissel S, Schmidt-Zachmann MS. A novel helicasetype protein in the nucleolus: protein NOH61. Mol Biol Cell. 2000;11(4): 1153-67 Available from: http://www.ncbi.nlm.nih.gov/pubmed/10749921.

107. Paranjape SM, Harris E. Y box-binding protein-1 binds to the dengue virus $3^{\prime}$-untranslated region and mediates antiviral effects. J Biol Chem. 2007; 282(42):30497-508

108. Phillips SL, Soderblom EJ, Bradrick SS, Garcia-Blanco MA. Identification of proteins bound to dengue viral RNA in vivo reveals new host proteins important for virus replication. MBio. 2016;7(1):e01865-15.

109. Yang Y, McBride KM, Hensley S, Lu Y, Chedin F. Bedford MT. Arginine methylation facilitates the recruitment of TOP3B to chromatin to prevent $R$ loop accumulation. Mol Cell. 2014;53(3):484-97 Available from: http://www. ncbi.nlm.nih.gov/pubmed/24507716.
110. Ahmad M, Xue Y, Lee SK, Martindale JL, Shen W, Li W, et al. RNA topoisomerase is prevalent in all domains of life and associates with polyribosomes in animals. Nucleic Acids Res. 2016;44(13):6335-49 Available from: http://www.ncbi.nlm.nih.gov/pubmed/27257063.

111. Hsu AYH, Wu SR, Tsai JJ, Chen PL, Chen YP, Chen TY, et al. Infectious dengue vesicles derived from CD61+ cells in acute patient plasma exhibited a diaphanous appearance. Sci Rep. 2015;11:5.

112. Vora A, Zhou W, Londono-Renteria B, Woodson M, Sherman MB, Colpitts TM, et al. Arthropod EVs mediate dengue virus transmission through interaction with a tetraspanin domain containing glycoprotein Tsp29Fb. Proc Natl Acad Sci U S A. 2018 Jul 10;115(28): E6604-13.

113. Martins S d T, Kuczera D, Lötvall J, Bordignon J, Alves LR. Characterization of dendritic cell-derived extracellular vesicles during dengue virus infection. Front Microbiol. 2018;9:1792.

114. Reyes-Ruiz JM, Osuna-Ramos JF, De Jesús-González LA, Hurtado-Monzón AM, Farfan-Morales CN, Cervantes-Salazar M, et al. Isolation and characterization of exosomes released from mosquito cells infected with dengue virus. Virus Res. 2019;266:1-14.

115. Zhou W, Woodson M, Sherman MB, Neelakanta G, Sultana H. Exosomes mediate Zika virus transmission through SMPD3 neutral Sphingomyelinase in cortical neurons. Emerg Microbes Infect. 2019;8(1):307-26.

116. Zhou W, Woodson M, Neupane B, Bai F, Sherman MB, Choi KH, et al. Exosomes serve as novel modes of tick-borne flavivirus transmission from arthropod to human cells and facilitates dissemination of viral RNA and proteins to the vertebrate neuronal cells. PLoS Pathog. 2018; 14(1):1-36.

117. Patton JG, Franklin JL, Weaver AM, Vickers K, Zhang B, Coffey RJ, et al. Biogenesis, delivery, and function of extracellular RNA. J Extracell Vesicles. 2015;4(1):1-9.

118. Kouwaki T, Okamoto M, Tsukamoto H, Fukushima Y, Oshiumi H. Extracellular vesicles deliver host and virus RNA and regulate innate immune response. Int J Mol Sci. 2017;18(3). https://doi.org/10.3390/ijms18030666. https://www. ncbi.nlm.nih.gov/pubmed/28335522.

119. Kim KM, Abdelmohsen K, Mustapic M, Kapogiannis D, Gorospe M. RNA in extracellular vesicles. Wiley Interdiscip Rev RNA. 2017;8(4):1-20.

120. Ressel S, Rosca A, Gordon K, Buck AH. Extracellular RNA in viral-host interactions: thinking outside the cell. Wiley Interdiscip Rev. 2019;10:e1535 RNA. Blackwell Publishing Ltd.

121. Février B, Raposo G. Exosomes: Endosomal-derived vesicles shipping extracellular messages. Curr Opin Cell Biol. 2004;16(4):415-21.

122. Khatua AK, Taylor HE, Hildreth JEK, Popik W. Exosomes packaging APOBEC3G confer human immunodeficiency virus resistance to recipient cells. J Virol. 2009;83(2):512-21.

123. Kalamvoki M, Du T, Roizman B. Cells infected with herpes simplex virus 1 export to uninfected cells exosomes containing STING, viral mRNAs, and microRNAs. Proc Natl Acad Sci U S A. 2014;111(46):E4991-6.

124. Ambros V. The functions of animal microRNAs. Nature. 2004;431(7006): 350-5 Available from: http://www.ncbi.nlm.nih.gov/pubmed/15372042.

125. Bartel DP. MicroRNAs: genomics, biogenesis, mechanism, and function. Cell. 2004;116(2):281-97.

126. Zhang J, Li S, Li L, Li M, Guo C, Yao J, et al. Exosome and exosomal microRNA: trafficking, sorting, and function. Genomics, Proteomics Bioinforma. 2015;13(1):17-24

127. Saadatpour L, Fadaee E, Fadaei S, Nassiri Mansour R, Mohammadi M, Mousavi SM, et al. Glioblastoma: exosome and microRNA as novel diagnosis biomarkers. Cancer Gene Ther. 2016;23(12):415-8 Available from: http:// www.ncbi.nlm.nih.gov/pubmed/27834360.

128. Yao Z-Y, Chen W-B, Shao S-S, Ma S-Z, Yang C-B, Li M-Z, et al. Role of exosome-associated microRNA in diagnostic and therapeutic applications to metabolic disorders. J Zhejiang Univ Sci B. 2018;19(3):183-98 Available from: http://www.ncbi.nlm.nih.gov/pubmed/29504312.

129. Valadi H, Ekström K, Bossios A, Sjöstrand M, Lee JJ, Lötvall JO. Exosomemediated transfer of mRNAs and microRNAs is a novel mechanism of genetic exchange between cells. Nat Cell Biol. 2007;9(6):654-9.

130. Batagov AO, Kurochkin IV. Exosomes secreted by human cells transport largely mRNA fragments that are enriched in the $3^{\prime}$-untranslated regions. Biol Direct. 2013;8(1):1-8.

131. Bellingham SA, Coleman BM, Hill AF. Small RNA deep sequencing reveals a distinct miRNA signature released in exosomes from prion-infected neuronal cells. Nucleic Acids Res. 2012;40(21):10937-49. 
132. Shurtleff MJ, Yao J, Qin Y, Nottingham RM, Temoche-Diaz MM, Schekman R, et al. Broad role for YBX1 in defining the small noncoding RNA composition of exosomes. Proc Natl Acad Sci U S A. 2017 Oct 24;114(43):E8987-95.

133. Villarroya-Beltri C, Gutiérrez-Vázquez C, Sánchez-Cabo F, Pérez-Hernández D, Vázquez J, Martin-Cofreces N, et al. Sumoylated hnRNPA2B1 controls the sorting of miRNAs into exosomes through binding to specific motifs. Nat Commun. 2013:4:1-10

134. Santangelo L, Giurato G, Cicchini C, Montaldo C, Mancone C, Tarallo R, et al. The RNA-binding Protein SYNCRIP is a component of the hepatocyte Exosomal machinery controlling MicroRNA sorting. Cell Rep. 2016;17(3):799_ 808. Available from:. https://doi.org/10.1016/j.celrep.2016.09.031.

135. Shurtleff MJ, Temoche-Diaz MM, Karfilis KV, Ri S, Schekman R. Y-box protein 1 is required to sort microRNAs into exosomes in cells and in a cell-free reaction. Elife. 2016;5 Available from: https://elifesciences.org/articles/19276.

136. Quaresma AJC, Bressan GC, Gava LM, Lanza DCF, Ramos CHI, Kobarg J. Human hnRNP Q re-localizes to cytoplasmic granules upon PMA, thapsigargin, arsenite and heat-shock treatments. Exp Cell Res. 2009;315(6): 968-80 Available from: http://www.ncbi.nlm.nih.gov/pubmed/19331829.

137. Martinez FJ, Pratt GA, Van Nostrand EL, Batra R, Huelga SC, Kapeli K, et al. Protein-RNA Networks Regulated by Normal and ALS-Associated Mutant HNRNPA2B1 in the Nervous System. Neuron. 2016;92(4):780-95 Available from: http://www.ncbi.n/m.nih.gov/pubmed/27773581.

138. Kedersha N, Anderson P. Mammalian stress granules and processing bodies. Methods Enzymol. 2007:431(07):61-81.

139. Frankel EB, Audhya A. ESCRT-dependent cargo sorting at multivesicular endosomes. Semin Cell Dev Biol. 2018; 74: 4-10. Available from: https://doi. org/10.1016/j.semcdb.2017.08.020.

140. Statello L, Maugeri M, Garre E, Nawaz M, Wahlgren J, Papadimitriou A, et al. Identification of RNA-binding proteins in exosomes capable of interacting with different types of RNA: RBP-facilitated transport of RNAs into exosomes. PloS One. 2018;13(4):1-30.

141. Chen YH, Du W, Hagemeijer MC, Takvorian PM, Pau C, Cali A, et al. Phosphatidylserine vesicles enable efficient en bloc transmission of enteroviruses. Cell. 2015;160(4):619-30.

142. Altan-Bonnet N, Perales C, Domingo E. Extracellular vesicles: Vehicles of en bloc viral transmission. Virus Res. 2019;265:143-9 Elsevier B.V.

143. Altan-Bonnet N. Extracellular vesicles are the Trojan horses of viral infection. Curr Opin Microbiol. 2016;32:77-81 Elsevier Ltd.

144. Ramakrishnaiah V, Thumann C, Fofana I, Habersetzer F, Pan Q, De Ruiter PE, et al. Exosome-mediated transmission of hepatitis $C$ virus between human hepatoma Huh7.5 cells. Proc Natl Acad Sci U S A. 2013;110(32):13109-13.

145. Bukong TN, Momen-Heravi F, Kodys K, Bala S, Szabo G. Exosomes from Hepatitis C Infected Patients Transmit HCV Infection and Contain Replication Competent Viral RNA in Complex with Ago2-miR122-HSP90. PLoS Pathog. 2014;10(10):e1004424.

146. Longatti A, Boyd B, Chisari FV. Virion-independent transfer of replicationcompetent Hepatitis C virus RNA between permissive cells. J Virol. 2015; 89(5):2956-61.

147. Jopling C, Yi M, Lancaster A. Modulation of hepatitis C virus RNA abundance by a liver-specific MicroRNA. Science (80- ). 2005; 309(September):1577-81.

148. Shimakami T, Yamane D, Jangra RK, Kempf BJ, Spaniel C, Barton DJ, et al. Stabilization of hepatitis C virus RNA by an Ago2-miR-122 complex. Proc Natl Acad Sci U S A. 2012;109(3):941-6 Available from: http://www.ncbi.nlm. nih.gov/pubmed/22215596.

149. Okamoto T, Nishimura Y, Ichimura T, Suzuki K, Miyamura T, Suzuki T, et al. Hepatitis C virus RNA replication is regulated by FKBP8 and Hsp90. EMBO J. 2006;25(20):5015-25 Available from: http://www.ncbi.n/m.nih.gov/pubmed/1 7024179 .

150. Ward AM, Bidet K, Yinglin A, Ler SG, Hogue K, Blackstock W, et al. Quantitative mass spectrometry of DENV-2 RNA-interacting proteins reveals that the DEAD-box RNA helicase DDX6 binds the DB1 and DB2 3' UTR structures. RNA Biol. 2011;8(6):1173-86 Available from: http://www. pubmedcentral.nih.gov/articlerender.fcgi?artid=3256426\&tool= pmcentrez\&rendertype=abstract.

151. Emara MM, Brinton M. a. Interaction of TIA-1/TIAR with West Nile and dengue virus products in infected cells interferes with stress granule formation and processing body assembly. Proc Natl Acad Sci U S A. 2007; 104(21):9041-6.

152. Chahar HS, Chen S, Manjunath N. P-body components LSM1, GW182, DDX3, DDX6 and XRN1 are recruited to WNV replication sites and positively regulate viral replication. Virology. 2013;436(1):1-7. Available from:. https:// doi.org/10.1016/j.virol.2012.09.041

153. Ward AM, Bidet K, Yinglin A, Ler SG, Hogue K, Blackstock W, et al. Quantitative mass spectrometry of DENV-2 RNA-interacting proteins reveals that the DEAD-box RNA helicase DDX6 binds the DB1 and DB2 3' UTR structures. RNA Biol. 2011;8(6):1173-86. Available from:. https://doi.org/10. 4161/rna.8.6.17836.

154. Albornoz A, Carletti T, Corazza G, Marcello A. The stress granule component TIA-1 binds tick-borne encephalitis virus RNA and is recruited to Perinuclear sites of viral replication to inhibit viral translation. J Virol. 2014;88(12):661122 Available from: http://www.ncbi.n/m.nih.gov/pubmed/24696465.

155. Diaz O, Delers F, Maynard M, Demignot S, Zoulim F, Chambaz J, et al. Preferential association of Hepatitis C virus with apolipoprotein B48containing lipoproteins. J Gen Virol. 2006;87(Pt 10):2983-91 Available from: http://www.ncbi.n/m.nih.gov/pubmed/16963757.

156. Chang K-S, Jiang J, Cai Z, Luo G. Human Apolipoprotein E is required for infectivity and production of Hepatitis C virus in Cell culture. J Virol. 2007; 81(24):13783-93.

157. Gould SJ, Booth AM, Hildreth JEK. The Trojan exosome hypothesis. Proc Natl Acad Sci U S A. 2003;100(19):10592-7.

158. Abernathy E, Mateo R, Majzoub K, van Buuren N, Bird SW, Carette JE, et al. Differential and convergent utilization of autophagy components by positive-strand RNA viruses. PLOS Biol. 2019;17(1):e2006926. Sugden B, editor. Available from. https://doi.org/10.1371/journal.pbio.2006926.

159. Heaton NS, Randall G. Dengue virus-induced autophagy regulates lipid metabolism. Cell Host Microbe. 2010;8(5):422-32 Available from: https:// linkinghub.elsevier.com/retrieve/pii/S1931312810003434.

160. Mateo R, Nagamine CM, Spagnolo J, Méndez E, Rahe M, Gale M, et al. Inhibition of cellular autophagy deranges dengue Virion maturation. J Virol. 2013;87(3):1312-21. Available from:. https://doi.org/10.1128/JVI.02177-12.

161. Blázquez AB, Martín-Acebes MA, Saiz JC. Amino acid substitutions in the non-structural proteins $4 A$ or $4 B$ modulate the induction of autophagy in West Nile virus infected cells independently of the activation of the unfolded protein response. Front Microbiol. 2015;5. Available from:. https:// doi.org/10.3389/fmicb.2014.00797/abstract.

162. Liang Q, Luo Z, Zeng J, Chen W, Foo S-S, Lee S-A, et al. Zika virus NS4A and NS4B proteins deregulate Akt-mTOR signaling in human fetal neural stem cells to inhibit neurogenesis and induce autophagy. Cell Stem Cell. 2016; 19(5):663-71 Available from: https://linkinghub.elsevier.com/retrieve/pii/S1 934590916302144

163. Leidal AM, Huang HH, Marsh T, Solvik T, Zhang D, Ye J, et al. The LC3conjugation machinery specifies the loading of RNA-binding proteins into extracellular vesicles. Nat Cell Biol. 2020; Available from: http://www.ncbi. nlm.nih.gov/pubmed/31932738.

\section{Publisher's Note}

Springer Nature remains neutral with regard to jurisdictional claims in published maps and institutional affiliations.

\section{Ready to submit your research? Choose BMC and benefit from:}

- fast, convenient online submission

- thorough peer review by experienced researchers in your field

- rapid publication on acceptance

- support for research data, including large and complex data types

- gold Open Access which fosters wider collaboration and increased citations

- maximum visibility for your research: over $100 \mathrm{M}$ website views per year

At $\mathrm{BMC}$, research is always in progress.

Learn more biomedcentral.com/submission 